\title{
INFLUÊNCIA DE DIFERENTES SISTEMAS DE SOLVENTE ÁGUA-ETANOL SOBRE AS PROPRIEDADES FÍSICO- QUÍMICAS E ESPECTROSCÓPICAS DOS COMPOSTOS MACROCÍCLICOS FEOFITINA E CLOROFILA $\alpha$
}

\author{
Leonardo M. Moreira, Máira R. Rodrigues e Hueder P. M. de Oliveira* \\ Universidade Camilo Castelo Branco, Rod. Pres. Dutra, km 138, 12247-004 São Jose dos Campos - SP, Brasil \\ Adriana Lima \\ Universidade do Vale do Paraíba, Av. Shishima Hifumi, 2911, 12244-000 São José dos Campos - SP, Brasil \\ Rafael R. S. Soares, Vagner R. Batistela, Adriana P. Gerola e Noboru Hioka
}

Departamento de Química, Universidade Estadual de Maringá, Av. Colombo, 5790, 87020-900 Maringá - PR, Brasil

Divinomar Severino e Mauricio S. Baptista

Instituto de Química, Universidade de São Paulo, CP 26077, 05599-970 São Paulo - SP, Brasil

Antônio Eduardo da Hora Machado

Instituto de Química, Universidade Federal de Uberlândia, Av. João Naves de Ávila, 2121, 38408-100 Uberlândia - MG, Brasil

Recebido em 12/12/08; aceito em 24/7/09; publicado na web em 8/1/10

\begin{abstract}
INFLUENCE OF DIFFERENT WATER-ETHANOL SOLVENT SYSTEMS ON THE SPECTROSCOPIC AND PHYSICOCHEMICAL PROPERTIES OF THE MACROCYCLIC COMPOUNDS PHEOPHYTIN AND CHLOROPHYLL $\alpha$. This work focus on the influence of solvent on the photophysical properties of chlorophyll $\alpha$ and pheophytin. Both compounds are related to the photosynthesis process and are considered prototypes of photosensitizers in Photodynamic Therapy. Fluorescence measurements were developed using water/ethanol mixtures at different compositions, since both solvents could be employed in biological applications. The spectroscopic properties of these compounds undergo profound changes depending on water content in the ethanol due to autoaggregation processes. The major hydrophobicity and the lower dielectric constant of ethanol when compared with water precluded significantly the auto-aggregation process of these compounds.
\end{abstract}

Keywords: chlorophyll $\alpha$; pheophytin; aggregation.

\section{INTRODUÇÃO}

Clorofila é um pigmento importante com função fundamental na fotossíntese em todos os vegetais autotróficos. ${ }^{1}$ Além disso, a clorofila é precursora de bacterioclorofilas, que são compostos importantes para várias bactérias fotossintéticas. ${ }^{2}$ Em virtude destes fatos decorre o alto interesse por estudos deste composto e seus derivados. Porém, devido à insolubilidade da clorofila em água, a maioria das pesquisas é feita utilizando uma mistura de água com solvente orgânico adequado. ${ }^{3}$

O conhecimento do processo de fotossíntese, isto é, de todo o processo de transformação da energia solar em energia química na reação da fotossíntese de bactérias, algas e plantas superiores, ainda representa um verdadeiro desafio, tanto do ponto de vista teórico como experimental. Dentre as clorofilas encontradas na natureza, a clorofila $\alpha$ é a mais frequente e tem papel fundamental como doadora de elétrons nas reações fotoquímicas de fotossíntese de oxigênio, nas quais dois tipos de fotossistemas, tipo I (PSI) e tipo II (PSII), trabalham cooperativamente sobre o fluxo de elétrons da água para $\mathrm{NADP}^{+}$. O cofator reduzido, NADPH, é então utilizado para a fixação do $\mathrm{CO}_{2} \cdot{ }^{4}$ Os fotossistemas I e II têm sido intensamente estudados na literatura..$^{5-7}$

A clorofila $\alpha$ é um derivado da porfirina classificada como clorina, contendo $\mathrm{Mg}^{2+}$ (Figura 1). Clorinas possuem um de seus aneis pirrólicos na forma reduzida quando comparadas com as porfirinas, resultando em uma maior absortividade molar nas bandas Q (transições eletrônicas $\pi-\pi^{*}$ ) devido a um decréscimo de simetria. Estas bandas apresentam comprimento de onda em torno de 600 $\mathrm{nm}$, portanto dentro da "janela fototerapêutica" relativa à Terapia

*e-mail: huederpaulo@yahoo.com.br.
Fotodinâmica (TFD), ${ }^{8}$ e por este motivo constituem uma importante classe de compostos empregados em TFD. ${ }^{9-12}$ Esta possibilidade tem estimulado os estudos sobre as propriedades fotofísicas de clorinas substituídas e não-substituídas. ${ }^{13,14}$

Entretanto, clorinas como a clorofila $\alpha$ têm uma longa cadeia apolar (Figura 1), o que confere elevado caráter hidrofóbico à sua estrutura, característica responsável pela maior tendência à autoagregação apresentada por esses compostos em solventes polares como, por exemplo, a água. A formação de agregados de clorofilas, clorinas e várias porfirinas sintéticas tem sido observada em diversos ambientes. O fenômeno de agregação e de dimerização de porfirinas e de metaloporfirinas desempenha um papel significativo no seu comportamento fotofísico em soluções aquosas, ${ }^{15,16}$ inclusive prejudicando significativamente o seu emprego clínico em TFD. ${ }^{17,18}$ Os auto-agregados podem ser induzidos de várias formas, tais como variações de pH e de concentração iônica, modificações de solventes, funcionalização de monômero e adição de surfactante ${ }^{19} \mathrm{e}$ são devidos a interações de van der Waals, ligações de hidrogênio, interações

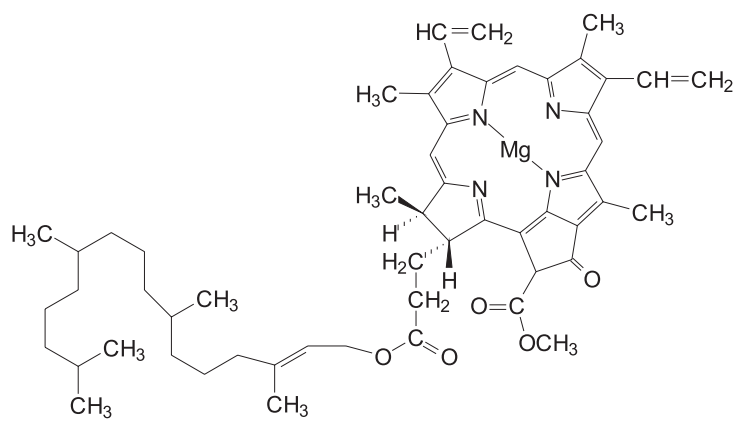

Figura 1. Estrutura da clorofila $\alpha$ 
eletrostáticas e ligações coordenadas metal-ligante. ${ }^{20}$

$\mathrm{O}$ rendimento quântico de produção de oxigênio molecular singleto $\left({ }^{1} \mathrm{O}_{2}\right)$ a partir de porfirinas em diferentes estados de agregação tem sido investigado na literatura. ${ }^{21,22}$ Esses estudos têm demonstrado que a fotoexcitação de compostos de uso clínico em TFD, como Photofrin ${ }^{\circledR}$, produz oxigênio molecular singlete com rendimentos significativamente menores do que a fotoexcitação de hematoporfirinas (Hp), o que leva à conclusão de que o rendimento quântico de produção de oxigênio singleto por um sensibilizador agregado é notavelmente menor do que aquele obtido a partir da forma monomérica. De fato, porfirinas agregadas e monoméricas apresentam diferenças de rendimentos quânticos, espectros de absorção e de fluorescência.

Embora Photofrin ${ }^{\circledR}$ tenha demonstrado ser eficaz no tratamento de muitos tipos de câncer, ele possui algumas propriedades indesejáveis, como a baixa absorção de luz dentro da "janela fototerapêutica", além de não ser rapidamente eliminado da pele causando fotossensibilização residual no paciente. Desta forma, vários grupos têm estudado protótipos fotossensibilizadores de segunda geração, tais como as clorinas, a fim de melhorar os resultados clínicos da TFD..$^{23}$

Clorofila $\alpha$ pode ser modificada gerando a feofitina (Pheo), onde o íon $\mathrm{Mg}^{2+}$ é substituído por dois átomos de hidrogênio. Este derivado pode ser obtido através de uma reação de hidrólise ácida (Figura 2). ${ }^{24}$ Na verdade, a transição clorofila-feofitina tem sido avaliada em várias condições, como em sílica mesoporosa, uma vez que esta reação é importante em várias abordagens tecnológicas. ${ }^{25}$
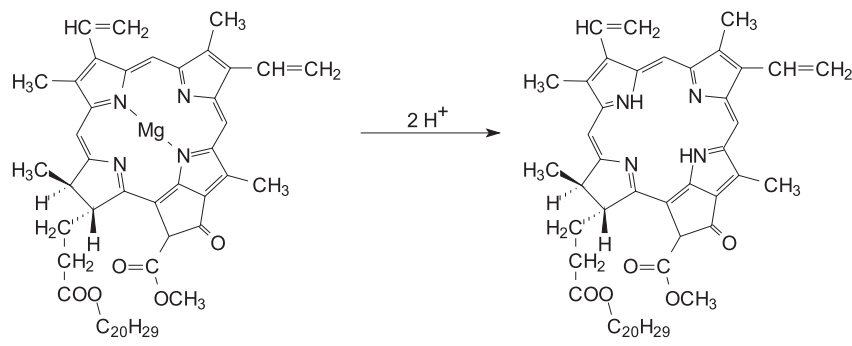

Figura 2. Esquema das reações de obtenção da feofitina a partir da clorofila $\alpha$ por hidrólise ácida

Outras clorofilas também podem ser sintetizadas através da substituição do centro metálico $\mathrm{Mg}^{2+}$ por $\mathrm{Cu}^{2+}$ e $\mathrm{Zn}^{2+}$. Particularmente, feofitina $\alpha$ apresenta maior tendência para a auto-agregação, quando comparada com clorofila, devido à ausência do centro catiônico e sua consequente maior hidrofobicidade. De fato, o íon metálico divalente aumenta a polaridade dos compostos macrocíclicos, atenuando o caráter hidrofóbico de todo o sistema químico.

O presente trabalho teve por objetivo avaliar a influência do tipo de sistema solvente sobre as propriedades espectroscópicas da clorofila $\alpha(\mathrm{Chl})$ e feofitina (Pheo), buscando encontrar condições ideais para aplicações de fotossensibilizadores em TFD.

\section{PARTE EXPERIMENTAL}

Chl e Pheo foram estudadas em soluções compostas de misturas água/etanol em diferentes composições. Foram preparadas onze soluções para cada fotossensibilizador $\left(5 \times 10^{-5} \mathrm{~mol} \mathrm{~L}^{-1}\right.$ da solução estoque contendo $\mathrm{Chl}$ ou Pheo, com concentrações respectivamente de $5,89 \times 10^{-4}$ e $3,95 \times 10^{-4} \mathrm{~mol} \mathrm{~L}^{-1}$, em $2 \times 10^{-3} \mathrm{~mol} \mathrm{~L}^{-1}$ de solução, resultando em soluções com as seguintes concentrações: [Chl] $=1,47$ x $10^{-6} \mathrm{~mol} \mathrm{~L}^{-1}$ e $\left[\right.$ Pheo] $=0,99 \times 10^{-6} \mathrm{~mol} \mathrm{~L}^{-1}$ ).

A água utilizada no preparo das soluções foi de grau Milli-Q e o etanol de grau espectroscópico. Os fotossensibilizadores Chl e Pheo foram obtidos a partir de extração do espinafre conforme sugerido por Dolphin, ${ }^{26}$ seguida de reação com ácido clorídrico $\left(2 \mathrm{~mol} \mathrm{~L}{ }^{-1}\right)$ em etanol. A purificação do sensibilizador foi feita por cromatografia (Chromatotron Harrison Research, modelo 8924) tendo sílica como fase estacionária. A caracterização foi realizada por $\mathrm{RMN}^{1} \mathrm{H}$ (Varian, Gemini $300 \mathrm{MHz}$ ).

Os espectros de absorção foram obtidos em um espectrofotômetro Cary-50 da Varian. Os espectros de excitação e emissão foram obtidos usando um espectrofluorímetro FloroMax-2 da Jobin-Yvon Spex $($ Fenda de emissão $=$ Fenda de excitação $=1 \mathrm{~mm})$. Os espectros de emissão foram obtidos usando o comprimento de onda de excitação correspondente ao de maior intensidade obtido nos espectros de excitação das amostras. Também foi utilizado um espectrofluorímetro Ocean Optics USB4000 configurado para fluorescência com Software SpectraSuite para medidas de emissão e espalhamento de luz.

Espectros de espalhamento de luz ressonante (RLS) foram obtidos no intervalo entre 200 e $800 \mathrm{~nm}$, com $\Delta \lambda=0 \mathrm{~nm}$ (modo sincrônico), a fim de monitorar o processo de auto-agregação. Cubetas de quartzo com caminho óptico de $1 \mathrm{~cm}$ foram empregadas nessas medidas.

\section{RESULTADOS E DISCUSSÃO}

Muitas pesquisas têm sido feitas no sentido de desenvolver e explorar agregados moleculares artificiais para emprego em dispositivos ópticos não-lineares, dentre outros, já que em geral essas estruturas tendem a apresentar propriedades adequadas para a conversão de frequências ópticas, processamento de informação, transmissão, armazenamento, tudo isso associado a baixos custos de processamento. ${ }^{27-30}$

Sob as condições experimentais aplicadas, os espectros de fluorescência da Chl e Pheo apresentaram alargamento nas bandas de emissão muito similares entre si. As intensidades das bandas variam de acordo com a razão entre os solventes. Para ambos fotossensibilizadores, os dados espectroscópicos relativos à intensidade de fluorescência demonstraram uma profunda dependência com a proporção de água na mistura de solventes.

A Figura 3 ilustra a relação entre a intensidade de excitação da Chl e a quantidade de água presente na mistura de solventes água/ etanol. Observa-se que a intensidade de excitação é maior em etanol puro, onde a espécie presente nas condições empregadas é a forma monomérica. A intensidade de excitação diminui significativamente nas misturas de solventes com maior conteúdo de água, em virtude do processo de auto-agregação do corante..$^{10}$ Este fato pode ser devido a características peculiares da água, sobretudo à sua grande tendência de formar ligações de hidrogênio. A alta polaridade conferida pela água ao sistema solvente tende a favorecer o surgimento de interações hidrofóbicas entre os monômeros da Chl, resultando em gradativa agregação ${ }^{1}$ à medida que a proporção de água aumenta no sistema. A formação de auto-agregados é ainda uma grande limitação para a aplicação de fotossensibilizadores em TFD. , $^{8,31}$

Os espectros de absorção desses compostos mostram-se igualmente sensíveis à composição da mistura de solventes. Através das inserções das Figuras 3 e 6 está claro que os compostos estão na forma monoméricas quando em etanol puro, com máximos de absorção na banda de Soret e na banda Q (a 665 e $667 \mathrm{~nm}$ para Chl e Pheo, respectivamente). À medida que a porcentagem de etanol diminui, observa-se uma perda de intensidade da banda $\mathrm{Q}$ referente ao monômero, fenômeno atribuído à auto-agregação. Para a Chl observa-se um pequeno deslocamento espectral, enquanto que para a Pheo há a formação de uma banda adicional em $692 \mathrm{~nm}$, muito provavelmente decorrente da absorção dos agregados. A presença ou ausência de novas bandas de absorção nos sistemas é explicada pela Teoria do Éxciton. ${ }^{33-35}$ Segundo essa teoria, a perda de estrutura e deslocamento para o vermelho da banda Q observada para esses compostos, sobretudo no caso da Feofitina, pode ser atribuída às 
interações intermoleculares decorrentes da agregação, resultando na formação de éxcitons, o que leva ao acoplamento das transições permitidas. Isso resulta em importantes alterações na fotofísica desses compostos, os quais podem se comportar como transportadores de cargas, como sugerido por Hoffmann, ${ }^{36}$ ou ao levantamento da degenerescência, aumentando o desdobramento da banda em decorrência de distorções moleculares. ${ }^{37-39}$ Em estudo recente, Machado e colaboradores, ${ }^{40}$ reportaram que o espectro de absorção de agregados de ftalocianina de zinco suportados em partículas nanométricas de óxido de titânio apresenta uma perda marcante na estrutura da banda Q decorrente das fortes interações intermoleculares entre moléculas de ftalocianina de zinco no éxciton formado. Ademais, com base nas características espectrais observadas, concluíram que esses éxcitons se comportam como agregados tipo J de Frenkel. ${ }^{36-40}$

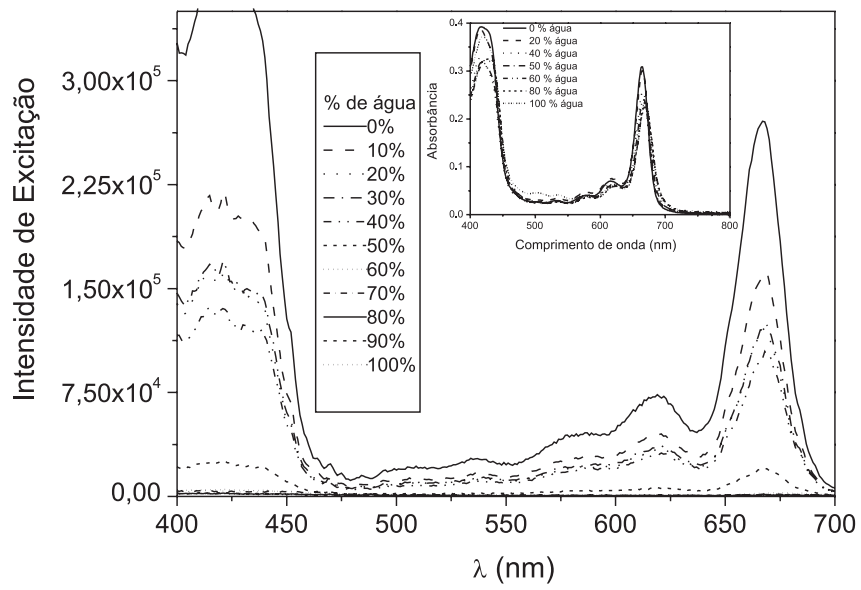

Figura 3. Espectro de excitação da clorofila $\alpha\left(\lambda_{e m}=680 \mathrm{~nm}\right)$ para diferentes misturas água/etanol. Inserto: Espectro de absorção da clorofila $\alpha$ para diferentes misturas água/etanol

As Figuras 4 e 5 apresentam a emissão de fluorescência da Chl em misturas etanol/água. A intensidade de fluorescência apresenta redução gradual no intervalo de 0 a $40 \%$ de água, e mais rapidamente entre 40 e $50 \%$. De fato, com $50 \%$ de água, essa banda apresenta diminuição mais significativa quando comparada às amostras com menor conteúdo de água. A partir de $60 \%$ de água, a fluorescência da Chl é completamente suprimida, o que sugere a ocorrência de um intenso processo de agregação. Além disso, é possível detectar um

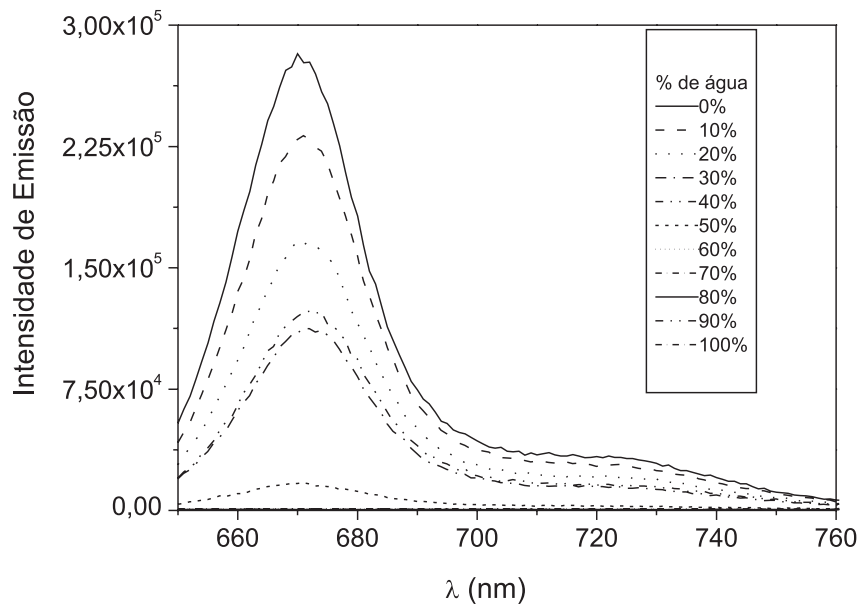

Figura 4. Espectros de emissão de fluorescência da clorofila $\alpha$ em misturas águaletanol. $\lambda_{\text {exc }}=667 \mathrm{~nm}$

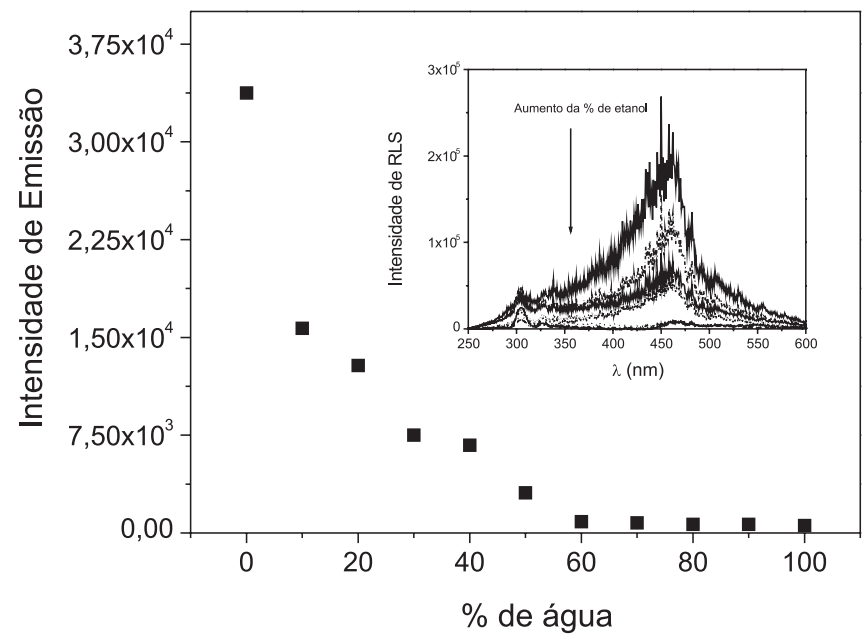

Figura 5. Variação do máximo de emissão da clorofila $\alpha$ em misturas águal etanol. $\lambda_{\text {exc }}=667 \mathrm{~nm}$. Inserto: Espectro RLS da clorofila $\alpha$ em diferentes misturas água/etanol

ligeiro deslocamento para o vermelho do máximo de emissão, especialmente na faixa entre 20 e $40 \%$ de água, o que sugere a formação de éxcitons em virtude do aumento da constante dielétrica do meio. ${ }^{37-39}$

O inserto da Figura 5 apresenta os experimentos de RLS, que estão de acordo com esta proposta, uma vez que sob alta porcentagem de etanol na mistura solvente o sinal RLS diminui, sugerindo uma menor proporção de agregados formados. Esses dados estão de acordo com os resultados obtidos por Agostiano, ${ }^{1}$ que detectou pequeno deslocamento bactocrômico da banda de absorção, atribuído a variações na constante dielétrica e nas interações específicas soluto-solvente, que acabam por favorecer a formação de agregados. ${ }^{1,38,39,41}$ Esse deslocamento ocorre porque, além das fortes interações intermoleculares entre as estruturas macrocíclicas, decorrente da formação dos agregados moleculares ${ }^{40} \mathrm{o}$ orbital antiligante $\pi$ é mais acessível e mais polarizável que o orbital ligante $\pi$, o que é favorecido por um aumento na polaridade do sistema de solventes. ${ }^{38-40,42-45}$

A Figura 6 apresenta os espectros de excitação da Pheo. Para misturas de solventes com maiores conteúdos de etanol os espectros exibem elevada intensidade de emissão de fluorescência, o que indica a presença de maiores proporções de monômeros isolados.

Os espectros de emissão da Pheo nas diferentes misturas águaetanol (Figura 7) sugerem que esta espécie é mais suscetível ao

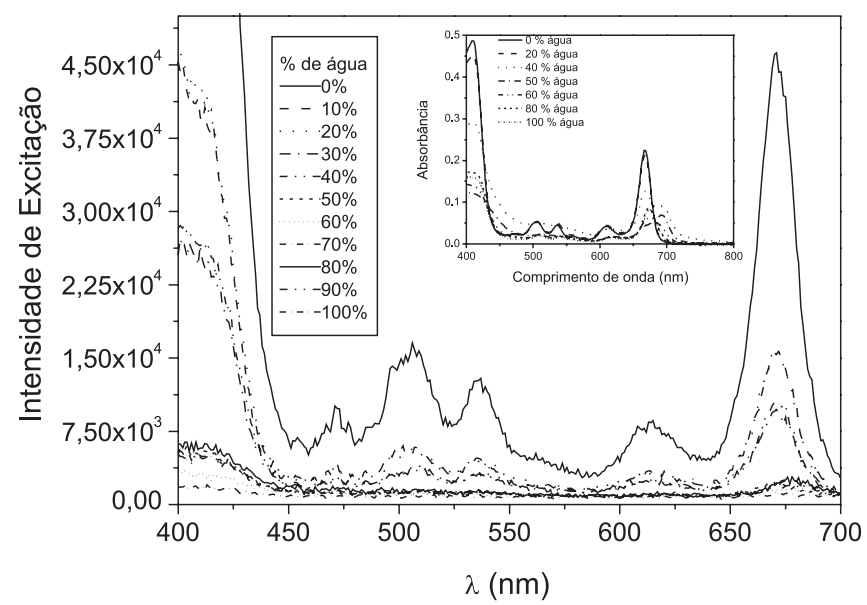

Figura 6. Espectro de excitação da feofitina $\left(\lambda_{e m}=680 \mathrm{~nm}\right)$ para diferentes misturas água/etanol. Inserto: Espectro de absorção da feofitina para diferentes misturas água/etanol 


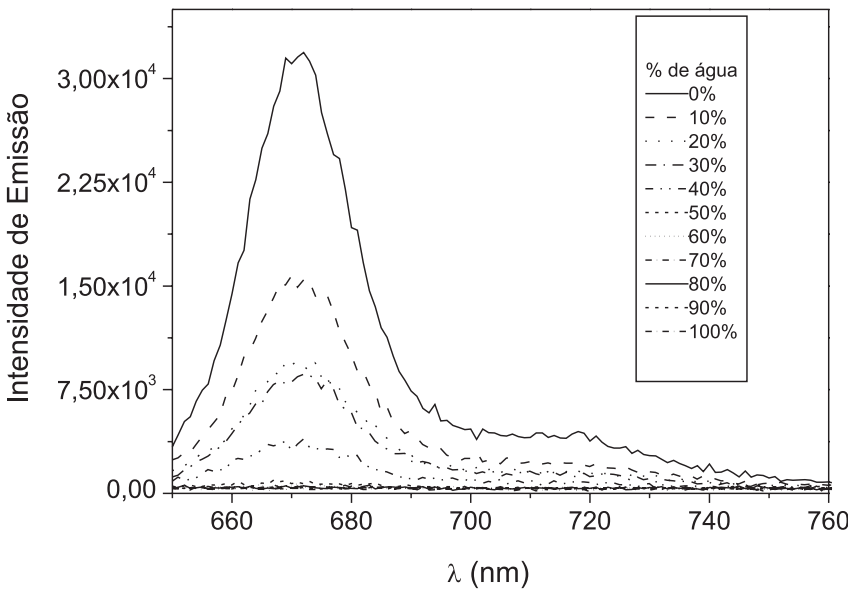

Figura 7. Espectros de emissão de fluorescência da feofitina em misturas águaletanol. $\lambda_{\text {exc }}=670 \mathrm{~nm}$

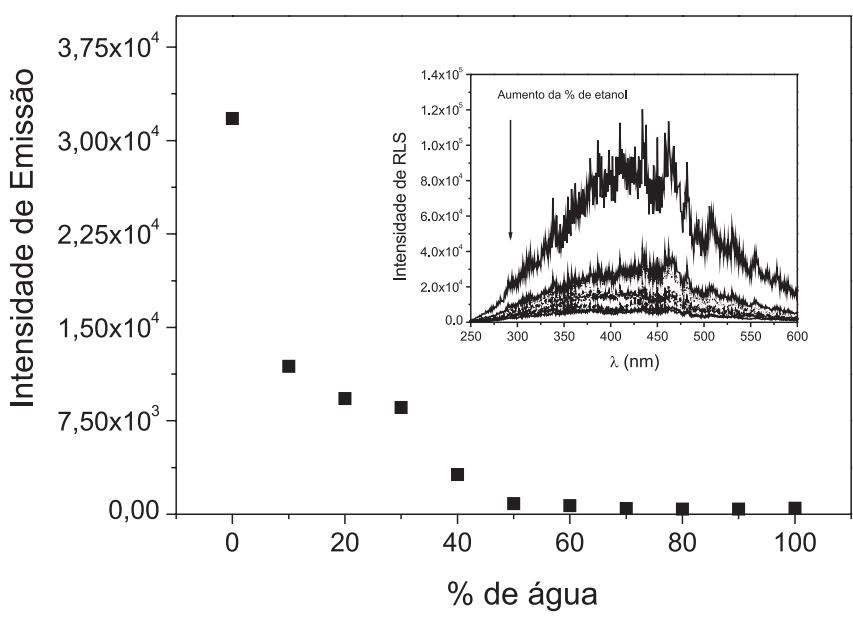

Figura 8. Variação do máximo de emissão da feofitina em misturas águal etanol. $\lambda_{\text {exc }}=670 \mathrm{~nm}$. Inserto: Espectro RLS da feofitina em diferentes misturas águaletanol

fenômeno de auto-agregação que a Chl, ocorrendo em menores proporções de água no solvente. Este fato provavelmente se deve à ausência de centros catiônicos nesta clorina, o que a torna menos hidrofílica. Desse modo, a supressão da fluorescência dessa espécie ocorre já a baixas porcentagens de água, como mostrado na Figura 8 .

A Figura 8 ilustra a dependência entre a intensidade de emissão de fluorescência da Pheo e a quantidade de água no meio. $\mathrm{O}$ inserto na Figura 8 mostra o crescente espalhamento de luz ressonante, o qual ocorre a uma taxa muito maior que a observada para a Chl, à medida que aumenta a concentração de água na mistura.

É evidente que a adição de um solvente orgânico como o etanol deva favorecer a ocorrência das formas monoméricas dos derivados de clorofila, o que é mostrado pelas altas intensidades de emissão e excitação. Apesar da significativa polaridade do etanol, este solvente é suficientemente anfifílico para desestabilizar os agregados formados em meio aquoso, já que a região hidrofóbica desse composto tende a favorecer a solvatação das unidades monoméricas dos corantes hidrofóbicos estudados. A ação anfifílica do etanol é semelhante à observada na interação entre derivados de porfirina e surfactantes. De fato, o equilíbrio dos agregados de derivados de porfirina, como as clorinas, nos sistemas micelas tem sido bastante estudado, desde que surfactantes e outros contra-íons podem alterar drasticamente a probabilidade de dimerização e agregação da base livre das porfirinas iônicas. ${ }^{46-49}$

A formação de agregados altera significativamente as propriedades físico-químicas dos compostos estudados, o que pode ser observado através das alterações nos seus espectros e em parâmetros fotofísicos, tais como rendimentos quânticos, tempo de vida dos estados singleto e tripleto e, consequentemente, com impacto negativo na produção de oxigênio molecular singleto..$^{1,17,26}$

\section{CONCLUSÃO}

Os corantes estudados no presente artigo apresentam propriedades de agregação semelhantes, dependentes da proporção água/etanol. Neste contexto, é importante registrar a significativa absorção eletrônica ao redor de $410 \mathrm{~nm}$, bem como a chamada "janela terapêutica", entre 660 e $670 \mathrm{~nm}$, com alta absortividade molar.

Devido à alta hidrofobicidade das clorinas Chl e Pheo, é esperado que o processo de auto-agregação ocorra em meio aquoso. O solvente aquoso apresenta características peculiares que induzem o processo de auto-agregação dos compostos macrocíclicos, tais como o grande potencial para formar ligações de hidrogênio, especialmente em amostras contendo grandes quantidades de água na mistura de solventes.

Este processo de agregação tende a ser intensificado, originando uma supressão de fluorescência acentuada, o que é corroborado pelos dados de RLS. É relevante notar que para a Pheo, o processo de autoagregação ocorre com menor participação de água, quando comparado com o sistema de solventes que promove a agregação de Chl. Isso é causado pela ausência do centro metálico na Pheo, que torna este composto mais hidrofóbico do que Chl. É claro que a presença de um solvente que alia ligações hidrogênio de um lado e cadeia alquílica de outro (caráter ligeiramente mais hidrofóbico) como etanol, atuando de maneira semelhante aos surfactantes, favorece a solubilidade de todo o sistema. Desta forma, as unidades de clorina são encontradas predominantemente na forma monomérica, o que impede o processo de agregação. Isto ocorre porque os monômeros de clorina são solvatados significativamente pelo etanol, que é bem conhecido como composto anfifílico. Com efeito, o etanol poderia agir de forma semelhante aos agentes ativos de superfície, comumente chamados surfactantes.

Estes dados espectroscópicos serão correlacionados com novas experiências, a fim de propor um solvente ótimo em proporção águasolvente orgânico. O estudo do sistema de solventes permitiria obter um meio excelente para desenvolver ensaios iniciais envolvendo Chl e Pheo como agente fototerapêutico para TFD, uma vez que agregação é uma dificuldade relevante para este tipo de aplicação, devido aos baixos rendimentos quânticos de geração de oxigênio singlete.

\section{AGRADECIMENTOS}

À FAPESP (06/56701-3; JP 02/00272-6), FAPEMIG (EDT515/05, CEX-652/05, CEX APQ-0571-5.02/08 e CEX 0122/08), CNPq (479655/2008-1 Edital Universal) e Nanobrax (www.nanobrax. com). A. Lima (IC), A. E. H. Machado (PQ 1-C), L. Codognoto (PQ 2) e N. Hioka (PQ 2) agradecem ao CNPq e à Fundação Araucária Brasil pelas bolsas concedidas.

\section{REFERÊNCIAS}

1. Agostiano, A.; Cosma, P.; Trotta, M.; Monsú-Scolaro, L.; Micali, N.; J. Phys. Chem. B 2002, 106, 12820.

2. Sasaki, S.; Mizoguchi, T.; Tamiaki, H.; J. Org. Chem. 2007, 72, 4566.

3. Agostiano, A.; Catucci, L.; Colafemmina, G.; Scheer, H.; J. Phys. Chem. 2002, 106, 1446.

4. Tomo, T.; Okubo, T.; Akimoto, S.; Yokono, M.; Miyashita, H.; Tsuchiya, T.; Noguchi, T.; Mimuro, M.; PNAS 2007, 104, 7283. 
5. Novoderezhkin, V. I.; Dekker, J. P.; van Grondelle, R.; Biophys. J. 2007, 93, 1293.

6. Groot, M. L.; Pawlowicz, N. P.; van Wilderen, L. J. G. W.; Breton, J.; van Stokkum, I. H. M.; van Grondelle, R.; PNAS 2005, 13, 1387.

7. Liu, S.; Dong, F.; Yang, C.; Tang, C.; Kuang, T.; J. Integr. Plant Biol. 2006, 48, 1330.

8. Moser, J. G.; Photodynamic Tumor Therapy - Generation Photosensitizers, $2^{\text {nd }}$ and $3^{\text {rd }}$ ed., Harwood: Índia, 1998.

9. Sternberg, E. D.; Dolphin, D.; Brükner, C.; Tetrahedron 1998, 54, 4151.

10. Simplicio, F. I.; Maionchi, F.; Santin Filho, O.; Hioka, N.; J. Phys. Org. Chem. 2004, 17, 325.

11. Delmarre, D.; Hioka, N.; Boch, R.; Sternberg, E.; Dolphin, D.; Can. J. Chem. 2001, 79, 1068.

12. Simplicio, F. I.; Maionchi, F.; Santin Filho, O.; Hioka, N.; J. Phys. Chem. A 2004, 108, 9384.

13. Kee, H. L.; Kirmaier, C.; Tang, Q.; Diers, J. R.; Muthiah, C.; Taniguchi, M.; Laha, J. K.; Ptaszek, M.; Lindsy, J. S.; Bocian, D. F.; Holten, D.; Photochem. Photobiol. 2007, 83, 1110.

14. Kee, H. L.; Kirmaier, C.; Tang, Q.; Diers, J. R.; Muthiah, C., M.; Taniguchi, J.; Laha, M.; Ptaszek, J. S.; Lindsey, D. F.; Bocian, D.; Holten, D.; Photochem. Photobiol. 2007, 83, 1125.

15. Pasternack, R. F.; Schaefer, K. F.; Hambright, P.; Inorg. Chem. 1994, 33 , 2062.

16. Ribó, J. M.; Crusats, J.; Farrera, J. A.; Valero, M. L.; J. Chem. Soc. Chem. Commum. 1994, 6, 681 .

17. Hioka, N.; Chowdhary, R. K.; Chansarkar, N.; Delmarre, D.; Sternberg, E.; Dolphin, D.; Can. J. Chem. 2002, 80, 1321.

18. Chowdhary, R. K.; Chansarkar, N.; Sharif, I.; Hioka, N.; Dolphin, D.; Photochem. Photobiol. 2003, 77, 299.

19. Mishra, P. P.; Bhatnagar, J.; Datta, A.; Chem. Phys. Lett. 2004, 386, 158.

20. Hu, J.; Guo, Y.; Liang, H.; Wan, L.; Jiang, L.; J. Am. Chem. Soc. 2005, 127, 17090.

21. Juzeniene, A.; Moan, J.; Photodiag. Photodyn. Ther. 2007, 4, 3.

22. Severino, D.; Junqueira, H. C.; Gabrielli, D. S.; Gugliotti, M.; Baptista, M. S.; Photochem. Photobiol 2003, 77, 459.

23. Hargus, J. A.; Fronczek, F. R.; Vicente, M. G. H.; Smith, K. M.; Photochem. Photobiol. 2007, 83, 1006.

24. Dujardin, E.; Laszio, P.; Sacks, D.; J. Chem. Educ. 1975, 52, 742.

25. Nakamura, T.; Takeuchi, M.; Yamashita, H.; Anpo, M.; Chem. Lett. 2006, 35, 106

26. Dolphin, D.; The porphyrins. Physical Chemistry Part C, Academic Press Inc.: New York, 1978.

27. Kanis, D. R.; Ratner, M. A.; Marks, T. J.; Chem. Rev. 1994, 94, 195.
28. Prasad, P. R.; Williams,D. J.; Introduction to nonlinear optical effects in molecules and polymers, Wiley-Interscience: New York, 1991.

29. Silva, A. M. S.; da Rocha, G. B.; Menezes, P. H.; Miller, J.; Simas, A. M.; J. Braz. Chem. Soc. 2005, 16, 583.

30. De Boni, L.; Rodrigues Jr., J. J.; dos Santos Jr., D. S.; Silva, C. H. T. P; Balogh, D. T.; Oliveira Jr., O. N.; Zílio, S. C.; Misoguti, L.; Mendonça, C. R.; Chem. Phys. Lett. 2002, 361, 209.

31. Björn, L. O. Em Photobiology: The Science of Life and Light; Björn, L. O., ed.; $2^{\text {nd }}$ ed.; Springer: New York, 2008.

32. Socaciu, C. Em Food Colorants: Chemical and Functional Properties; Socaciu, C., ed.; CRC Press: New York, 2007.

33. Nitta, H.; Shoji, M.; Takahata, M.; Nakanob, M.; Yamaki, D.; Yamaguchi, K.; J. Photochem. Photobiol. A 2006, 178, 264.

34. Kasha, M. A.; Radiat. Res. 1963, 20, 55.

35. Tessaro, A. L.; Fernandes, D. M.; Terezo, A. J.; Souza, V. R.; Hioka, N.; J. Porph. Phthal. 2005, 9, 609.

36. Hoffmann, M.; Ph.D. Thesis, Technische Universität Dresden, Germany, 2000

37. Mi, J.; Guo, L.; Liu,Y.; Liu, W.; You, G.; Qian, S.; Phys. Lett. A 2003 , 310, 486.

38. Mizuguchi, J.; Matsumoto, S.; J. Phys. Chem. A 1999, 103, 614

39. Davydov, A. S.; Theory of Molecular Excitons, McGraw-Hill: New York, 1962.

40. Machado, A. E. H.; França, M. D.; Velani, V.; Magnino, G. A.; Velani, H. M. M.; Freitas, F. S.; Müller Jr., P. S.; Sattler, C.; Schmücker, M.; Int. J. Photoen. 2008, 2008, 1.

41. Mizoguchi, T.; Limantara, L.; Matsuura, K.; Shimada, K.; Koyama, Y.; Mol. Struct. 1996, 379, 249.

42. Moreira, L. M.; Santiago, P. S.; de Almeida, E. V.; Tabak, M.; Colloids Surf. B 2008, 61, 153.

43. Santiago, P. S.; Moreira, L. M.; de Almeida, E. V.; Tabak. M.; Biochim. Biophys. Acta 2007, 1770, 506.

44. Ribelatto, J. C.; Poli, A. L.; Moreira, L. M.; Imasato, H.; Quim. Nova 2006, 29, 666.

45. Ribelatto, J. C.; Poli, A. L.; Moreira, L. M.; Imasato, H.; Quim. Nova 2005, 28, 829.

46. Li, X.; Li, D.; Han, M.; Chen, Z.; Zou, G.; Colloids Surf. A 2005, 256, 151.

47. Tominaga, T.; Endoh, S.; Ishimaru, H.; Water Bull. Chem. Soc. Jpn. 1991, 64, 942.

48. Kadish, K. M.; Maiya, G. B.; Araullo, C.; Guilard, R.; Inorg. Chem. 1989, 28, 2725 .

49. Gandini, S. C. M.; Yushmanov, V. E.; Borissevitch, I. E.; Tabak, M.; Langmuir 1999, 15, 6233. 